\title{
Carbon mineralization dynamics in soils after wildfires in two Galician forests
}

\author{
I. Fernández, A. Cabaneiro, T. Carballas* \\ Instituto de Investigaciones Agrobiológicas de Galicia, C.S.I.C. Apartado 122, 15780 Santiago de Compostela, Spain.
}

Accepted 24 June 1999

\begin{abstract}
The carbon mineralization dynamics of two Humic Cambisols, developed over granite, one under Pinus sylvestris L. (1740 $\mathrm{m}$ a.s.1.) and the other under Pinus pinaster Aiton (140 m a.s.1.), were determined in samples of $0-5$ and 5-10 cm depth collected after high intensity wildfires. Burnt and unburnt soils were sampled five times over 2 yr after the wildfires to determine changes in $\mathrm{C}$ concentration and in potential mineralization activity of the soil organic matter. Soil samples from the same forests unaffected by the fires were used as controls. In both soils the fire resulted in a substantial decrease in the soil carbon concentration. Immediately after the fire, the $\mathrm{C}$ mineralization was decreased in the surface layer; however, the percentage of total $\mathrm{C}$ mineralized increased in both layers. The evolution of these variables over time depended on the soil and on the layer considered. During the first months after the burning the $\mathrm{C}$ mineralization presented values lower than those of the control in both layers of the soil located at higher altitude (M) and in the surface layer of the other soil (R), but values higher than those of the control in the subsurface layer of soil R. For the same period, the $\mathrm{C}$ mineralization coefficient in the surface layer was similar to (M) or lower than (R) that of the corresponding control, whereas in the subsurface layer it was maintained above that of the control in both soils. Two years after the fire, the total $\mathrm{C}$ concentration had been recovered in the surface layer of both soils whereas in the subsurface layers its value was still 15-19\% lower than that of the same layer in the corresponding control. At the same time, the $\mathrm{C}$ mineralization and the percentage of the total $\mathrm{C}$ mineralized in the surface layer of the burnt soils were lower than those in the corresponding unburnt soils. In the subsurface layer, soil $\mathrm{M}$ exhibited values of these two mineralization indices higher than those of the control, whereas soil $\mathrm{R}$ presented values lower than those of the control from $1 \mathrm{yr}$ after the fire. The cumulative $\mathrm{CO}_{2}-\mathrm{C}$ evolved by the samples during each incubation fits two kinetic models: a simple and a double exponential first order equation. In most cases the coefficient of determination $\left(R^{2}\right)$ was higher for the double exponential model. The fire affected the kinetic parameters; the effect was ephemeral on the labile $\mathrm{C}$ pool, which increased its content $\left(\mathrm{C}_{0}\right)$ and its mineralization rate $(k)$, but more persistent on the recalcitrant fraction, which shows a long-term decrease of its instantaneous mineralization rate $(h)$. According to principal components analysis, the variability of the samples studied is mainly due to differences on their organic matter quality and, in a smaller proportion, to differences in organic matter concentration. The effect of fire on these factors, which was more pronounced in the soil with the initially higher $\mathrm{C}$ concentration, persisted during the 2 yr study. (C) 1999 Elsevier Science Ltd. All rights reserved.
\end{abstract}

Keywords: Burning; C mineralization; Forest soils; Organic matter activity; Soil recovery

\section{Introduction}

Soil organic matter mineralization affects soil fertility and is conditioned by many factors e.g. type of

\footnotetext{
* Corresponding author. Fax: +34-981-592-504.

E-mail addresses: ifernandez@cesga.es (I. Fernández), acabaneiro@cesga.es (A. Cabaneiro), tcf@cesga.es (T. Carballas)
}

soil, humus-layer quality and moisture content (Merilä and Ohtonen, 1997), temperature (Wildung et al., 1975), irradiation (Wen et al., 1997), tillage and soil texture (Franzluebbers and Arshad, 1997) and profile depth (Rovira and Vallejo, 1997). Due to its importance and complexity it is a widely studied process (Bekku et al., 1996; Pomazkina et al., 1996).

Forest plantations of the world total approximately 
Table 1

Main properties of the $0-5$ and 5-10 $\mathrm{cm}$ depth layers from the burnt soil M, located in Cabeza de Manzaneda (mean \pm S.E.M.; $n=3$ replicates) and mean values of the corresponding unburnt soil for a $2 \mathrm{yr}$ period (mean (S.D.); $n=5$ )

\begin{tabular}{|c|c|c|c|c|c|c|c|c|c|c|}
\hline Depth (cm) & Sample & Time after fire & $\mathrm{pH} \mathrm{KCl}$ & $\mathrm{C}\left(\mathrm{g} \mathrm{kg}^{-1}\right)$ & $\mathrm{C} / \mathrm{N}$ & $\mathrm{N}\left(\mathrm{g} \mathrm{kg}^{-1}\right)$ & $\mathrm{Fe}_{2} \mathrm{O}_{3}\left(\mathrm{~g} \mathrm{~kg}^{-1}\right)$ & $\mathrm{Al}_{2} \mathrm{O}_{3}\left(\mathrm{~g} \mathrm{~kg}^{-1}\right)$ & CEC (meq $100 \mathrm{~g}^{-1}$ ) & BS $(\%)$ \\
\hline \multirow[t]{6}{*}{$0-5$} & unburnt & $0-2 \mathrm{yr}$ & $3.39(0.24)$ & $125.4(33.9)$ & $19(2)$ & $6.57(1.70)$ & $5.4(0.8)$ & $6.3(1.0)$ & $49.2(11.3)$ & $4.4(1.3)$ \\
\hline & burnt 1 & $1 \mathrm{~d}$ & $4.00 \pm 0.00$ & $74.4 \pm 0.6$ & 15 & $4.87 \pm 0.09$ & $4.9 \pm 0.2$ & $6.1 \pm 0.2$ & $24.2 \pm 0.9$ & $13.2 \pm 0.2$ \\
\hline & burnt 2 & $1 \mathrm{~m}$ & $4.01 \pm 0.00$ & $73.5 \pm 0.7$ & 17 & $4.23 \pm 0.04$ & $5.9 \pm 0.1$ & $5.3 \pm 0.1$ & $25.4 \pm 0.2$ & $7.9 \pm 0.1$ \\
\hline & burnt 3 & $8 \mathrm{~m}$ & $3.60 \pm 0.00$ & $70.6 \pm 3.8$ & 15 & $4.81 \pm 0.12$ & $4.1 \pm 0.1$ & $4.9 \pm 0.0$ & $26.8 \pm 0.2$ & $6.7 \pm 0.0$ \\
\hline & burnt 4 & $1 \mathrm{yr}$ & $3.65 \pm 0.01$ & $103.8 \pm 0.7$ & 18 & $5.64 \pm 0.06$ & $3.7 \pm 0.1$ & $4.3 \pm 0.1$ & $25.0 \pm 0.1$ & $9.6 \pm 0.2$ \\
\hline & burnt 5 & $2 \mathrm{yr}$ & $3.65 \pm 0.01$ & $83.0 \pm 0.3$ & 18 & $4.56 \pm 0.02$ & $4.9 \pm 0.0$ & $5.0 \pm 0.1$ & $28.7 \pm 0.7$ & $6.5 \pm 0.2$ \\
\hline \multirow[t]{6}{*}{$5-10$} & unburnt & $0-2 \mathrm{yr}$ & $3.48(0.24)$ & $104.0(22.1)$ & $18(2)$ & $5.67(0.82)$ & $6.0(1.1)$ & $7.3(1.4)$ & $45.4(4.4)$ & $2.6(0.9)$ \\
\hline & burnt 1 & $1 \mathrm{~d}$ & $3.78 \pm 0.02$ & $51.1 \pm 1.2$ & 15 & $3.31 \pm 0.04$ & $4.7 \pm 0.0$ & $6.1 \pm 0.1$ & $33.8 \pm 0.6$ & $3.6 \pm 0.1$ \\
\hline & burnt 2 & $1 \mathrm{~m}$ & $3.83 \pm 0.00$ & $56.8 \pm 0.4$ & 20 & $2.82 \pm 0.02$ & $4.5 \pm 0.1$ & $5.0 \pm 0.1$ & $29.9 \pm 0.5$ & $3.2 \pm 0.1$ \\
\hline & burnt 3 & $8 \mathrm{~m}$ & $3.60 \pm 0.01$ & $57.3 \pm 0.5$ & 19 & $3.00 \pm 0.02$ & $4.2 \pm 0.0$ & $5.1 \pm 0.1$ & $26.2 \pm 0.1$ & $2.7 \pm 0.1$ \\
\hline & burnt 4 & $1 \mathrm{yr}$ & $3.55 \pm 0.01$ & $71.8 \pm 0.8$ & 19 & $3.86 \pm 0.02$ & $3.9 \pm 0.0$ & $4.7 \pm 0.1$ & $29.6 \pm 0.4$ & $3.9 \pm 0.1$ \\
\hline & burnt 5 & $2 \mathrm{yr}$ & $3.58 \pm 0.02$ & $72.2 \pm 0.4$ & 19 & $3.85 \pm 0.04$ & $5.2 \pm 0.0$ & $5.3 \pm 0.2$ & $28.6 \pm 1.1$ & $3.6 \pm 0.1$ \\
\hline
\end{tabular}

$130 \times 10^{6}$ ha with annual rates of establishment of about $10.5 \times 10^{6}$ ha (Winjum and Schroeder, 1997) and play an important role in sequestering and storing carbon in terrestrial ecosystems (Sampson, 1995). When natural ecosystems are altered, the organic matter turnover is modified and can alter both productivity and community structure of ecosystems (Pastor and Post, 1986), because of its influence on the supply of nutrients to plants (Berg and Tamm, 1991), on the composition of organic matter in the humus layer (Wardle, 1992) and on soil structure. In the last few decades, wildfire proliferation has become a widespread problem in Mediterranean European countries (Sanroque et al., 1985), even affecting regions until now considered of low fire risk, such as Galicia (DíazFierros et al., 1982). Wildfires not only destroy the soil organic matter and produces soil erosion (Chandler et al., 1983) but also results in the alteration of the mineralization dynamics of the organic matter that remains in the soil after the fire (Bauhus et al., 1993; Prieto-Fernández et al., 1993; Fernández et al., 1997).
Although this problem is very important, studies on this topic are scarce.

Taking into account the importance of the content and quality of the soil organic matter in the ecosystems, the $\mathrm{C}$ mineralization activity could be considered as a suitable indicator of the immediate effects of fires on the soil and of the subsequent soil recovery rate. Therefore, our objective was to study the C mineralization in two Galician forest soils, which were strongly affected by wildfires (Fernández et al., 1997). The study was conducted for 2 yr after the burning because it is in this period when the secondary succession of the vegetation registers the most important increases in cover and biomass (Casal, 1985).

\section{Materials and methods}

The soils selected for the study were two Humic Cambisols under pine forests with approximately $20 \mathrm{yr}$ old trees, developed over granite, which had been affected by wildfires. Both soils (M and R) are located

Table 2

Main properties of the $0-5$ and $5-10 \mathrm{~cm}$ depth layers from the burnt soil R, located in Caldas de Reis (mean \pm S.E.M.; $n=3$ replicates) and mean values of the corresponding unburnt soil for a two year period (mean (S.D.); $n=5$ )

\begin{tabular}{|c|c|c|c|c|c|c|c|c|c|c|}
\hline Depth $(\mathrm{cm})$ & Sample & Time after fire & $\mathrm{pH} \mathrm{KCl}$ & $\mathrm{C}\left(\mathrm{g} \mathrm{kg}^{-1}\right)$ & $\mathrm{C} / \mathrm{N}$ & $\mathrm{N}\left(\mathrm{g} \mathrm{kg}^{-1}\right)$ & $\mathrm{Fe}_{2} \mathrm{O}_{3}\left(\mathrm{~g} \mathrm{~kg}^{-1}\right)$ & $\mathrm{Al}_{2} \mathrm{O}_{3}\left(\mathrm{~g} \mathrm{~kg}^{-1}\right)$ & CEC (meq $100 \mathrm{~g}^{-1}$ ) & BS $(\%)$ \\
\hline \multirow[t]{6}{*}{$0-5$} & unburnt & $0-2 \mathrm{yr}$ & $3.56(0.22)$ & $94.6(15.6)$ & $16(1)$ & $5.83(0.80)$ & $8.5(1.8)$ & $8.6(2.3)$ & $42.6(3.3)$ & $2.4(0.4)$ \\
\hline & burnt 1 & $1 \mathrm{~m}$ & $3.81 \pm 0.01$ & $86.9 \pm 0.2$ & 12 & $7.18 \pm 0.01$ & $10.2 \pm 0.4$ & $5.5 \pm 0.2$ & $28.8 \pm 0.1$ & $4.4 \pm 0.1$ \\
\hline & burnt 2 & $4 \mathrm{~m}$ & $3.65 \pm 0.00$ & $120.8 \pm 0.4$ & 16 & $7.81 \pm 0.04$ & $11.9 \pm 0.0$ & $10.0 \pm 0.1$ & $37.8 \pm 0.4$ & $5.4 \pm 0.1$ \\
\hline & burnt 3 & $7 \mathrm{~m}$ & $3.61 \pm 0.01$ & $108.0 \pm 0.6$ & 14 & $7.60 \pm 0.05$ & $12.1 \pm 0.1$ & $8.6 \pm 0.2$ & $40.0 \pm 0.4$ & $3.9 \pm 0.0$ \\
\hline & burnt 4 & $1 \mathrm{yr}$ & $3.21 \pm 0.03$ & $98.8 \pm 0.2$ & 15 & $6.69 \pm 0.02$ & $10.2 \pm 0.0$ & $8.2 \pm 0.1$ & $35.9 \pm 0.3$ & $2.9 \pm 0.2$ \\
\hline & burnt 5 & $2 \mathrm{yr}$ & $3.10 \pm 0.00$ & $118.1 \pm 3.6$ & 16 & $7.24 \pm 0.09$ & $8.3 \pm 0.1$ & $5.7 \pm 0.1$ & $45.9 \pm 0.7$ & $2.9 \pm 0.1$ \\
\hline \multirow[t]{6}{*}{$5-10$} & unburnt & $0-2 \mathrm{yr}$ & $3.57(0.23)$ & $89.5(18.7)$ & $15(1)$ & $5.80(0.93)$ & $8.9(1.6)$ & $8.7(3.0)$ & $43.4(5.5)$ & $1.2(0.4)$ \\
\hline & burnt 1 & $1 \mathrm{~m}$ & $3.61 \pm 0.01$ & $93.7 \pm 0.4$ & 14 & $6.85 \pm 0.02$ & $11.6 \pm 0.2$ & $9.9 \pm 0.2$ & $46.0 \pm 0.6$ & $0.8 \pm 0.0$ \\
\hline & burnt 2 & $4 \mathrm{~m}$ & $3.60 \pm 0.00$ & $92.9 \pm 0.1$ & 14 & $6.66 \pm 0.07$ & $12.7 \pm 0.1$ & $10.3 \pm 1.0$ & $44.4 \pm 0.8$ & $1.2 \pm 0.1$ \\
\hline & burnt 3 & $7 \mathrm{~m}$ & $3.64 \pm 0.00$ & $94.5 \pm 0.4$ & 14 & $6.79 \pm 0.05$ & $12.6 \pm 0.1$ & $11.2 \pm 0.5$ & $46.1 \pm 0.8$ & $1.5 \pm 0.1$ \\
\hline & burnt 4 & $1 \mathrm{yr}$ & $3.49 \pm 0.00$ & $85.1 \pm 0.1$ & 14 & $6.18 \pm 0.06$ & $10.4 \pm 0.1$ & $10.0 \pm 0.4$ & $45.6 \pm 0.1$ & $1.1 \pm 0.1$ \\
\hline & burnt 5 & $2 \mathrm{yr}$ & $3.40 \pm 0.00$ & $82.2 \pm 0.7$ & 14 & $5.96 \pm 0.02$ & $10.1 \pm 0.4$ & $8.1 \pm 0.4$ & $41.9 \pm 0.6$ & $0.7 \pm 0.0$ \\
\hline
\end{tabular}


in Galicia (northwest Spain) within the humid temperate zone but in different climatic conditions due to their different altitudes. Soil $\mathrm{M}$ is located in Cabeza de Manzaneda (Orense) at $1740 \mathrm{~m}$ a.s.1., where the annual rainfall was approximately $2000 \mathrm{~mm}$ and the annual mean temperature $6^{\circ} \mathrm{C}$, with minima of $-4^{\circ} \mathrm{C}$ and maxima of $22^{\circ} \mathrm{C}$. This soil sustains a forest of Pinus sylvestris $\mathrm{L}$. and the undergrowth was composed of Chamaespartium tridentatum (L.) P. Gibbs, Vaccinium myrtillus L., Erica spp and species of Gramineae. Soil $\mathrm{R}$ is located at approximately $100 \mathrm{~km}$ from soil $\mathrm{M}$, in Caldas de Reis (Pontevedra) at $140 \mathrm{~m}$ a.s.l., where the annual rainfall was approximately $1800 \mathrm{~mm}$ and the annual mean temperature $14^{\circ} \mathrm{C}$, with minima of $5^{\circ} \mathrm{C}$ and maxima of $26^{\circ} \mathrm{C}$. This soil sustains a forest of Pinus pinaster Aiton with undergrowth of Ulex europaeus L., Pteridium aquilinum (L.) Kuhn and diverse herbaceous plants.

Both soils are acidic, sandy and unsaturated. The main differences between $\mathrm{M}$ and $\mathrm{R}$ are the higher concentration of carbon and the lower concentration of alteration compounds $\left(\mathrm{Fe}_{2} \mathrm{O}_{3}, \mathrm{Al}_{2} \mathrm{O}_{3}\right)$ in soil $\mathrm{M}$, located at a higher altitude (Tables 1 and 2). In both cases, part of the forest in the same topographic position was not burnt, which allowed the use of the unburnt soils as controls. Less than $100 \mathrm{~m}$ separate the burnt soil plots from their controls. Both the burnt and the unburnt plots belong to the same edaphic formation, with no difference in their geomorphology (Guitián Ojea and Carballas, 1982; Guitián Ojea et al., 1986).

Both wildfires were high intensity accidental fires (Chandler et al., 1983) of late summer; in both cases the undergrowth and the litter disappeared, the trees died, the burnt soils presented a white ashes cover and the mean depth of the soil penetrated by the fire was about $5 \mathrm{~cm}$.

To better follow the changes of the potential $\mathrm{C}$ mineralization after the fire, the intervals between successive soil samplings were short at the beginning of the experiment because it was possible that for some soil characteristics the changes happen quickly after burning. During the $2 \mathrm{yr}$ of the experiment, five samplings were performed for each soil. Soil $\mathrm{M}$ was collected $1 \mathrm{~d}$ and 1, 8, 12 and 24 months (samplings 1, 2, 3, 4 and 5 , respectively) after the fire. Soil $\mathrm{R}$ was collected 1,4 , 7, 12 and 24 months (samplings 1, 2, 3, 4 and 5, respectively) after the fire. The control soils were sampled at the same intervals.

In the burnt areas, a plot of $10 \times 10 \mathrm{~m}$ was established and protected with a metallic fence during the 2 $\mathrm{yr}$ of the experiment to avoid external interference. After the removal from the surface of the dry pine needles fallen from the dead trees after the burning, soil samples were collected every time from the A horizon at $0-5$ and $5-10 \mathrm{~cm}$ depth all along a new continuous profile $10 \mathrm{~m}$ in length inside the plot, gathering more than $10 \mathrm{~kg}$ of each burnt sample. Soil samples from the unburnt soils ( $\mathrm{M}$ and $\mathrm{R}$ ) were collected at the same sampling intervals and at the same depth as in the corresponding burnt soils, taking a great number of samples at random. All samples were sieved and the fraction less than $4 \mathrm{~mm}$ was homogenized. Fresh samples were used for the study of potential C mineralization. Air dried samples were employed for the determination of organic $\mathrm{C}$ and the other soil characteristics. The results were adjusted to oven-dry basis.

The methods described by Guitián Ojea and Carballas (1976) were used to determine the following soil properties: field capacity (at $10 \mathrm{kPa}$ in a Richard's membrane-plate extractor); $\mathrm{pH}$ in $1 \mathrm{~N} \mathrm{KCl}$ (1:2.5); extractable $\mathrm{Fe}$ and $\mathrm{Al}$ oxides (by extraction with a mixture of hydrosulphite and Tamm's reagent). $\mathrm{C}$ concentration was determined by combustion and measurement of the $\mathrm{CO}_{2}$ in a Carmhograph 12 with the primary oven at $900^{\circ} \mathrm{C}$ and the secondary oven at $400^{\circ} \mathrm{C}$. Total $\mathrm{N}$ concentration was determined by Kjeldahl digestion using the method of Bremner (1965). The results are the average of three replicate determinations using different subsamples of the same material.

Fresh samples, or samples stored at $4^{\circ} \mathrm{C}$ for less than 1 week, were used for the determination of $\mathrm{C}$ mineralization kinetics by aerobic incubation of soil samples. The incubation method was that of Guckert et al. (1968) modified by Choné et al. (1974), who used an intermittent air flow for aeration. Five replicates of $50 \mathrm{~g}$ soil from each sample were placed in $500 \mathrm{ml}$ Erlenmeyer flasks and maintained at $28^{\circ} \mathrm{C}$ and $75 \%$ of field capacity for 11 week. The atmosphere of the flasks was renewed periodically with humidified and $\mathrm{CO}_{2}$-free air and the $\mathrm{CO}_{2}$ evolved was trapped by bubbling for $2 \mathrm{~h}$ in $40 \mathrm{ml}$ of $2 \mathrm{~N} \mathrm{NaOH}$. From $5 \mathrm{ml}$ $\mathrm{NaOH}$ solution, the $\mathrm{Na}_{2} \mathrm{CO}_{3}$ formed was precipitated by $20 \% \mathrm{BaCl}_{2}$ solution and then the remaining $\mathrm{NaOH}$ was measured by titration against $0.2 \mathrm{~N} \mathrm{HCl}$ using a Metrohm 682 titrator. The $\mathrm{CO}_{2}-\mathrm{C}$ was then quantified by subtraction, using two empty flasks incubated under the same conditions as the control (GonzálezPrieto et al., 1991; Fernández et al., 1997). The potential $\mathrm{C}$ mineralization, expressed as $\mathrm{g}$ of $\mathrm{CO}_{2}-\mathrm{C}$ evolved $\mathrm{kg}^{-1}$ of dry soil and the percentage of the total $\mathrm{C}$ that was mineralized ( $\mathrm{C}$ mineralization coefficient) were calculated.

The cumulative curves of $\mathrm{CO}_{2}-\mathrm{C}$ released over time (means of five replicates) were fitted to the simple firstorder kinetic model $\left(\mathrm{C}_{t}=\mathrm{C}_{0}\left(1-\mathrm{e}^{-k t}\right)\right)$ proposed by Stanford and Smith (1972) and the double exponential model $\left(\mathrm{C}_{t}=\mathrm{C}_{0}\left(1-\mathrm{e}^{-k t}\right)+\left(\mathrm{TC}-\mathrm{C}_{0}\right)\left(1-\mathrm{e}^{-h t}\right)\right)$ proposed by Andrén and Paustian (1987), to quantify the kinetics of $\mathrm{C}$ released from soils $\mathrm{M}$ and $\mathrm{R}$. These two 


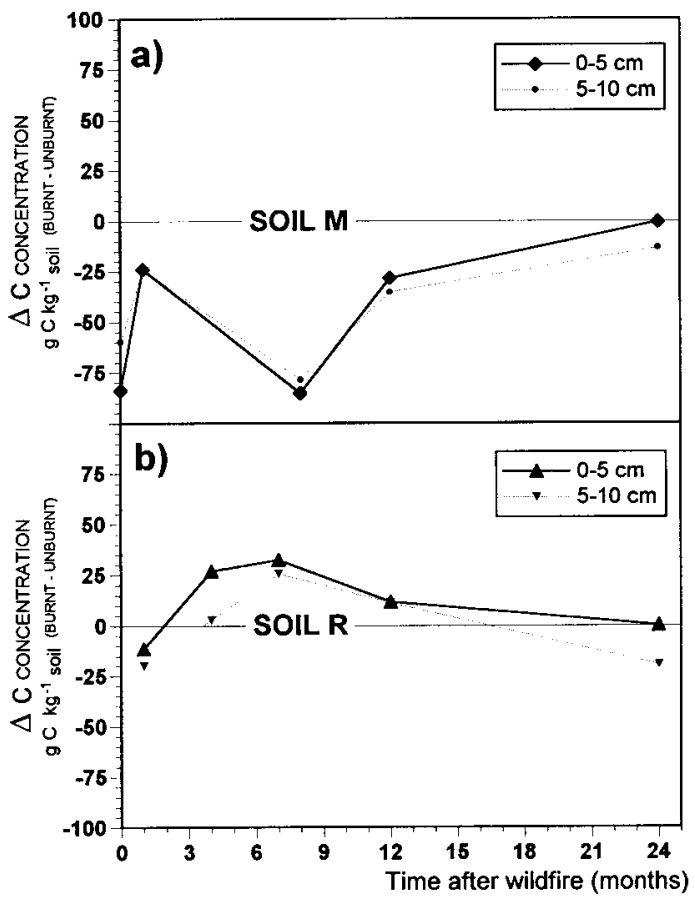

Fig. 1. Effects of fire on $\mathrm{C}$ concentration, expressed as differences between the burnt samples and the corresponding unburnt samples, for the surface $(0-5 \mathrm{~cm})$ and the subsurface $(5-10 \mathrm{~cm})$ layers of soils $\mathrm{M}$ (a) and $\mathrm{R}$ (b), throughout $2 \mathrm{yr}$ following a wildfire.

models are based on divergent hypotheses. The first model considers a unique $\mathrm{C}$ pool with a unique mineralization rate, whereas for the second one there are two $\mathrm{C}$ pools of different lability and therefore with different instantaneous mineralization rates. In the simple exponential model, $\mathrm{C}_{t}$ is the cumulative $\mathrm{C}$ released after time $t$ (day), $\mathrm{C}_{0}$ is the potentially mineralizable $\mathrm{C}$ and $k\left(\mathrm{~d}^{-1}\right)$ is the instantaneous release rate. In the double exponential model, $\mathrm{C}_{t}$ is the cumulative $\mathrm{C}$ released after time $t$ (day), $\mathrm{C}_{0}$ is the potentially mineralizable $\mathrm{C}$ in a labile pool with an instantaneous mineralization rate $k\left(\mathrm{~d}^{-1}\right)$, TC is the total amount of $\mathrm{C}$ present in the soil sample $\left(\mathrm{g} \mathrm{kg}^{-1}\right)$ and $\left(\mathrm{TC}-\mathrm{C}_{0}\right)$ is the amount of $\mathrm{C}$ in a recalcitrant pool with an instantaneous mineralization rate $h\left(\mathrm{~d}^{-1}\right)$. The non-linear parameter estimation procedures in SPSS.5.0.1 for Windows were used to fit the experimental data to the model. To avoid errors in the parameter estimation the convergence criteria indicated by Updegraff et al. (1995) were used.

The $\mathrm{C}$ mineralization data of each incubation were studied using a two-way Anova test, where the factors considered were fire (burnt/unburnt) and location of the layer in the profile (surface/subsurface), to follow the kinetic variations during the incubation as well as to know if there was a significant interaction between both factors. The computer program SPSS 5.0.1 was used. The least significant difference (LSD) test

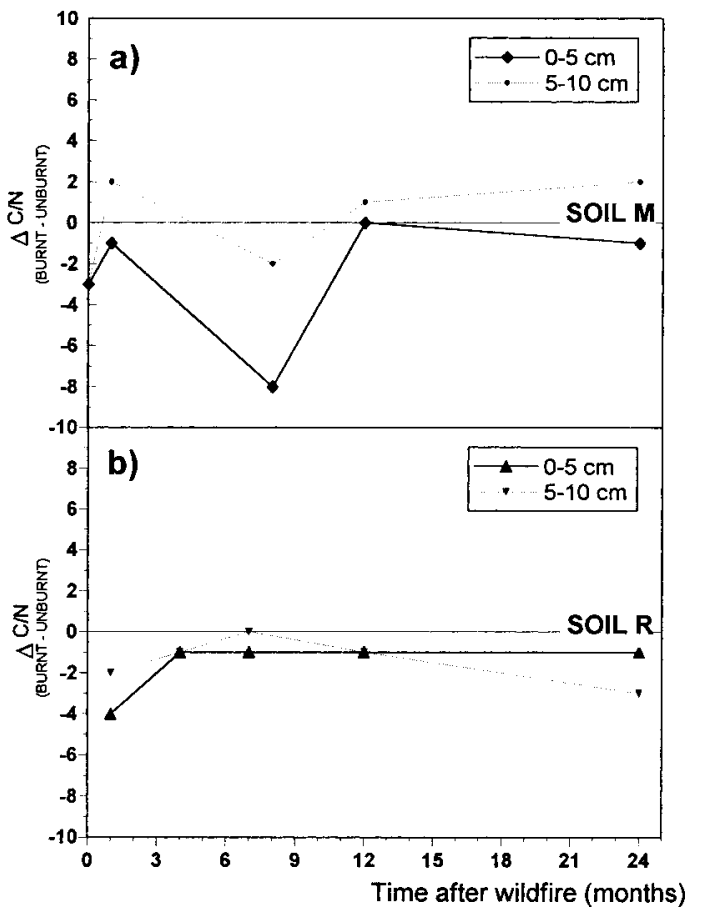

Fig. 2. Effects of fire on the $\mathrm{C} / \mathrm{N}$ ratio, expressed as differences between the burnt samples and the corresponding unburnt samples, for the surface $(0-5 \mathrm{~cm})$ and the subsurface $(5-10 \mathrm{~cm})$ layers of soils $\mathrm{M}$ (a) and R (b), throughout $2 \mathrm{yr}$ following a wildfire.

(Tukey, 1953) at the $95 \%$ probability level was applied to the results. To simplify the interpretation of the results a principal components analysis with varimax rotation, using the computer program SPSS 5.0.1, was utilized, with the purpose of showing the relationships between variables and to identify the possible soil factors controlling the recovery of the carbon mineralization activity in the burnt soils.

\section{Results and discussion}

\subsection{Carbon concentration and $\mathrm{C} / \mathrm{N}$ ratio}

The fire produced a significant initial decrease of soil C concentration (Tables 1 and 2; Fig. 1). This was particularly observed immediately after the burning in soil $\mathrm{M}$, with losses of 53 and $54 \%$ of the organic $\mathrm{C}$ in the surface and the subsurface layers, respectively. The change in the $\mathrm{C}$ concentration over the study period differed between the two soils. In the surface layer, soil $\mathrm{R}$ recovered the $\mathrm{C}$ concentration very quickly; 4 month after the fire the $\mathrm{C}$ concentration in the burnt soil was higher than that of the unburnt soil (Fig.1). In the same layer of soil $\mathrm{M}$ the recovery occurred much later, probably due to the winter freezing that affected this soil, located at high altitude. Two years after the burning, when the recovery of the vegetation 
Table 3

Cumulative $\mathrm{C}$ mineralization and $\mathrm{C}$ mineralization coefficient for 11 week incubation of the $0-5$ and $5-10 \mathrm{~cm}$ depth layers from each of five samplings of the burnt soils $\mathrm{M}$ and $\mathrm{R}$ (mean $\pm \mathrm{SEM} ; n=5$ )

\begin{tabular}{|c|c|c|c|c|c|c|c|}
\hline \multirow{2}{*}{$\begin{array}{l}\text { Depth } \\
(\mathrm{cm})\end{array}$} & \multirow[t]{2}{*}{ Sample } & \multicolumn{3}{|c|}{ Soil M } & \multicolumn{3}{|c|}{ Soil R } \\
\hline & & Time after fire & $\begin{array}{l}\mathrm{C} \text { mineralization } \\
\left(\mathrm{g} \mathrm{C} \mathrm{kg}^{-1}\right)\end{array}$ & $\begin{array}{l}\mathrm{C} \text { mineralization coefficient } \\
\left(\mathrm{g} \mathrm{C} 100 \mathrm{~g}^{-1} \mathrm{TC}\right)^{\mathrm{a}}\end{array}$ & Time after fire & $\begin{array}{l}\mathrm{C} \text { mineralization } \\
\left(\mathrm{g} \mathrm{C} \mathrm{kg}^{-1}\right)\end{array}$ & $\begin{array}{l}\mathrm{C} \text { mineralization coefficient } \\
\left(\mathrm{g} \mathrm{C} 100 \mathrm{~g}^{-1} \mathrm{TC}\right)^{\mathrm{a}}\end{array}$ \\
\hline \multirow[t]{5}{*}{$0-5$} & burnt 1 & $1 \mathrm{~d}$ & $2.58 \pm 0.03$ & $3.47 \pm 0.05$ & $1 \mathrm{~m}$ & $1.81 \pm 0.04$ & $2.09 \pm 0.10$ \\
\hline & burnt 2 & $1 \mathrm{~m}$ & $2.27 \pm 0.02$ & $3.09 \pm 0.03$ & $4 \mathrm{~m}$ & $2.62 \pm 0.08$ & $2.17 \pm 0.14$ \\
\hline & burnt 3 & $8 \mathrm{~m}$ & $1.85 \pm 0.03$ & $2.63 \pm 0.04$ & $7 \mathrm{~m}$ & $2.28 \pm 0.02$ & $2.11 \pm 0.04$ \\
\hline & burnt 4 & $1 \mathrm{yr}$ & $3.22 \pm 0.07$ & $3.11 \pm 0.06$ & $1 \mathrm{yr}$ & $1.54 \pm 0.04$ & $1.56 \pm 0.08$ \\
\hline & burnt 5 & $2 \mathrm{yr}$ & $1.94 \pm 0.03$ & $2.34 \pm 0.03$ & $2 \mathrm{yr}$ & $4.92 \pm 0.34$ & $4.17 \pm 0.65$ \\
\hline \multirow[t]{5}{*}{$5-10$} & burnt 1 & $1 \mathrm{~d}$ & $1.99 \pm 0.03$ & $3.89 \pm 0.05$ & $1 \mathrm{~m}$ & $2.13 \pm 0.05$ & $2.27 \pm 0.12$ \\
\hline & burnt 2 & $1 \mathrm{~m}$ & $1.76 \pm 0.01$ & $3.10 \pm 0.03$ & $4 \mathrm{~m}$ & $2.43 \pm 0.01$ & $2.62 \pm 0.04$ \\
\hline & burnt 3 & $8 \mathrm{~m}$ & $1.39 \pm 0.01$ & $2.43 \pm 0.03$ & $7 \mathrm{~m}$ & $1.81 \pm 0.05$ & $1.92 \pm 0.11$ \\
\hline & burnt 4 & $1 \mathrm{yr}$ & $2.40 \pm 0.03$ & $3.34 \pm 0.04$ & $1 \mathrm{yr}$ & $1.04 \pm 0.05$ & $1.22 \pm 0.13$ \\
\hline & burnt 5 & $2 \mathrm{yr}$ & $1.54 \pm 0.02$ & $2.39 \pm 0.03$ & $2 \mathrm{yr}$ & $2.79 \pm 0.18$ & $3.40 \pm 0.49$ \\
\hline
\end{tabular}

${ }^{\mathrm{a}} \mathrm{TC}$, total carbon.

cover had already started, $\mathrm{C}$ concentrations in the surface layer of both soils were similar to those of the corresponding control soils, with differences lower than $1 \%$. In the subsurface layer, the recovery of $\mathrm{C}$ concentration was slower than in the surface layer and at the end of the study the $\mathrm{C}$ concentration in the subsurface layers of soils $\mathrm{M}$ and $\mathrm{R}$ was still 15 and $19 \%$ lower, respectively, than in the corresponding controls. The increases in $\mathrm{C}$ concentration during the first year after the fire can only be attributed to unburnt remains from dead roots which disintegrate and slowly incorporate into the soil, as revegetation during this period was very scarce in both soils. According to Trabaud (1983), subterranean plant organs, located near the soil

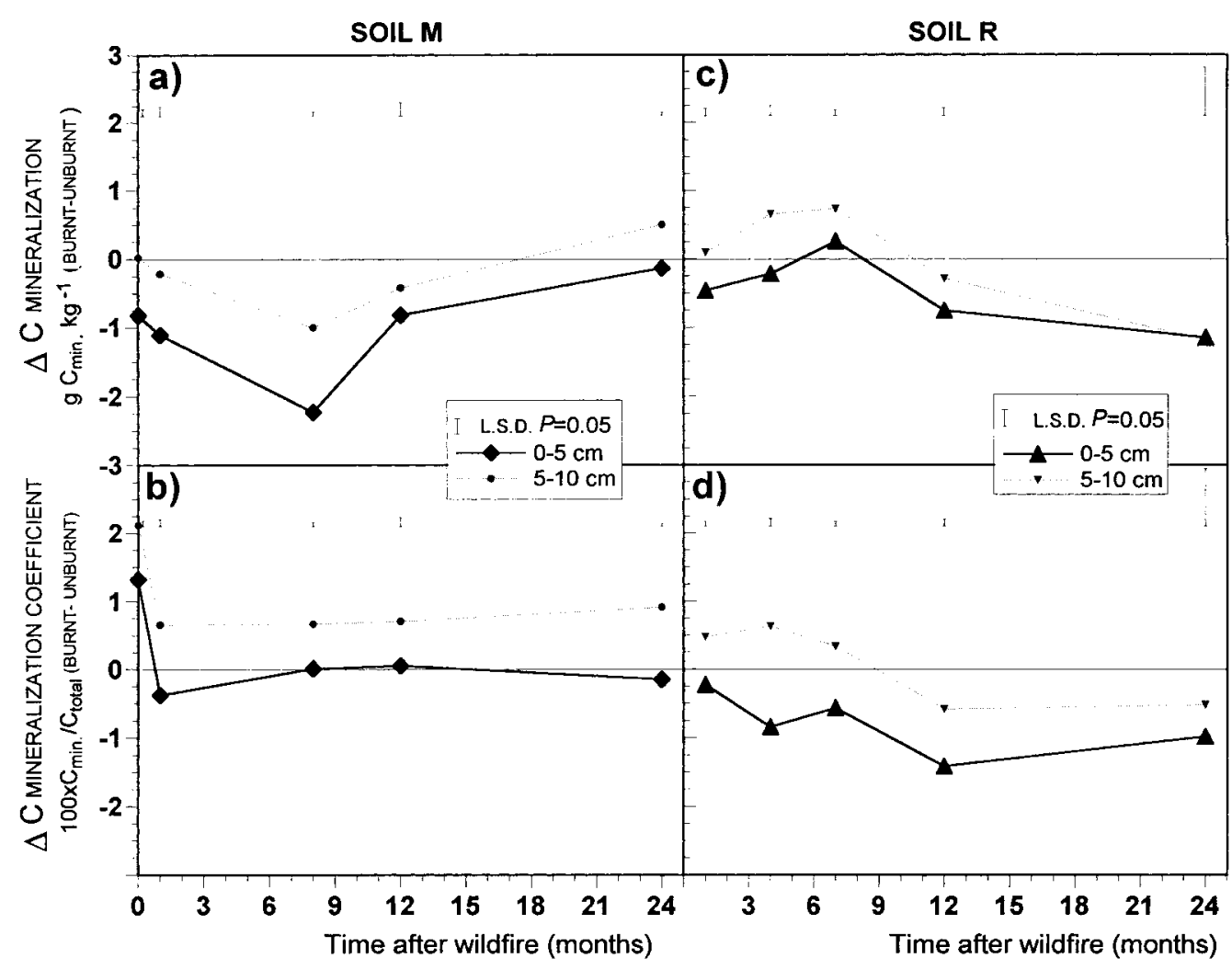

Fig. 3. Effects of fire on the $\mathrm{C}$ mineralization and the $\mathrm{C}$ mineralization coefficient, expressed as differences between the burnt samples and the corresponding unburnt samples, for the surface $(0-5 \mathrm{~cm})$ and the subsurface $(5-10 \mathrm{~cm})$ layers of soils $\mathrm{M}$ and $\mathrm{R}$, during $2 \mathrm{yr}$ after a wildfire. 
Table 4

Kinetic parameters for $\mathrm{C}$ mineralization models based on double first order exponential equation: $\mathrm{C}_{t}=\mathrm{C}_{0}\left(1-\mathrm{e}^{-k t}\right)+\left(\mathrm{TC}-\mathrm{C}_{0}\right)\left(1-\mathrm{e}^{-h t}\right)$, for cumulative $\mathrm{C}$ mineralization in the $0-5$ and $5-10 \mathrm{~cm}$ depth layers of the burnt soils $\mathrm{M}$ and $\mathrm{R}$ (estimated values \pm asymptotic standard error) and differences $(\Delta)$ between the kinetic parameters of the burnt and the corresponding unburnt soil samples ${ }^{\mathrm{a}}$

\begin{tabular}{|c|c|c|c|c|c|c|c|c|c|c|}
\hline \multirow[t]{2}{*}{ Soil } & \multirow[t]{2}{*}{ Depth $(\mathrm{cm})$} & \multirow[t]{2}{*}{ Sample } & \multirow[t]{2}{*}{ Time after fire } & \multirow[t]{2}{*}{$\mathrm{C}_{0}\left(\mathrm{~g} \mathrm{~kg}^{-1}\right)$} & \multirow[t]{2}{*}{$k\left(\mathrm{~d}^{-1}\right)$} & \multirow[t]{2}{*}{$h \times 10^{4}\left(\mathrm{~d}^{-1}\right)$} & \multirow[t]{2}{*}{$\mathrm{R}^{2}$} & \multicolumn{3}{|c|}{$\Delta$ (Burnt - unburnt $)$} \\
\hline & & & & & & & & $\mathrm{C}_{0}\left(\mathrm{~g} \mathrm{~kg}^{-1}\right)$ & $k\left(\mathrm{~d}^{-1}\right)$ & $h \times 10^{4}\left(\mathrm{~d}^{-1}\right)$ \\
\hline \multirow[t]{10}{*}{ Soil M } & \multirow[t]{5}{*}{$0-5$} & burnt 1 & $1 \mathrm{~d}$ & $1.06 \pm 0.02$ & $0.184 \pm 0.008$ & $2.80 \pm 0.06$ & 0.9986 & 0.39 & 0.079 & 0.51 \\
\hline & & burnt 2 & $1 \mathrm{~m}$ & $0.80 \pm 0.03$ & $0.120 \pm 0.009$ & $2.72 \pm 0.09$ & 0.9981 & -0.16 & 0.038 & -0.61 \\
\hline & & burnt 3 & $8 \mathrm{~m}$ & $0.49 \pm 0.02$ & $0.079 \pm 0.004$ & $2.60 \pm 0.04$ & 0.9997 & -0.41 & -0.026 & -0.11 \\
\hline & & burnt 4 & $1 \mathrm{yr}$ & $1.85 \pm 0.09$ & $0.047 \pm 0.002$ & $1.82 \pm 0.11$ & 0.9997 & 0.32 & -0.016 & -0.72 \\
\hline & & burnt 5 & $2 \mathrm{yr}$ & $0.56 \pm 0.02$ & $0.065 \pm 0.002$ & $2.19 \pm 0.03$ & 0.9999 & -0.06 & -0.007 & -0.11 \\
\hline & \multirow[t]{5}{*}{$5-10$} & burnt 1 & $1 \mathrm{~d}$ & $0.47 \pm 0.01$ & $0.173 \pm 0.008$ & $3.98 \pm 0.04$ & 0.9996 & 0.13 & 0.014 & 2.04 \\
\hline & & burnt 2 & $1 \mathrm{~m}$ & $0.41 \pm 0.01$ & $0.173 \pm 0.009$ & $3.17 \pm 0.04$ & 0.9994 & -0.09 & 0.070 & 0.73 \\
\hline & & burnt 3 & $8 \mathrm{~m}$ & $0.33 \pm 0.02$ & $0.095 \pm 0.009$ & $2.44 \pm 0.06$ & 0.9991 & -0.24 & 0.000 & 0.67 \\
\hline & & burnt 4 & $1 \mathrm{yr}$ & $1.20 \pm 0.09$ & $0.047 \pm 0.003$ & $2.28 \pm 0.16$ & 0.9995 & -0.01 & -0.003 & 0.26 \\
\hline & & burnt 5 & $2 \mathrm{yr}$ & $0.28 \pm 0.02$ & $0.082 \pm 0.006$ & $2.30 \pm 0.04$ & 0.9997 & -0.09 & 0.019 & 1.26 \\
\hline \multirow[t]{10}{*}{ Soil R } & \multirow[t]{5}{*}{$0-5$} & burnt 1 & $1 \mathrm{~m}$ & $0.77 \pm 0.02$ & $0.097 \pm 0.004$ & $1.60 \pm 0.04$ & 0.9993 & 0.31 & 0.007 & -0.84 \\
\hline & & burnt 2 & $4 \mathrm{~m}$ & $1.60 \pm 0.07$ & $0.044 \pm 0.002$ & $1.19 \pm 0.08$ & 0.9997 & 0.91 & -0.032 & -1.83 \\
\hline & & burnt 3 & $7 \mathrm{~m}$ & $1.14 \pm 0.05$ & $0.053 \pm 0.002$ & $1.42 \pm 0.07$ & 0.9997 & 0.61 & -0.034 & -1.20 \\
\hline & & burnt 4 & $1 \mathrm{yr}$ & $0.51 \pm 0.02$ & $0.091 \pm 0.006$ & $1.40 \pm 0.04$ & 0.9992 & -0.15 & 0.008 & -1.12 \\
\hline & & burnt 5 & $2 \mathrm{yr}$ & $6.39 \pm 0.23^{b}$ & $0.019 \pm 0.001^{\mathrm{b}}$ & & $0.9960^{\mathrm{b}}$ & -3.30 & 0.006 & \\
\hline & \multirow[t]{5}{*}{$5-10$} & burnt 1 & $1 \mathrm{~m}$ & $1.02 \pm 0.02$ & $0.126 \pm 0.005$ & $1.58 \pm 0.05$ & 0.9988 & 0.71 & -0.035 & -0.43 \\
\hline & & burnt 2 & $4 \mathrm{~m}$ & $1.39 \pm 0.05$ & $0.052 \pm 0.002$ & $1.53 \pm 0.07$ & 0.9997 & 0.70 & -0.006 & -0.07 \\
\hline & & burnt 3 & $7 \mathrm{~m}$ & $1.04 \pm 0.04$ & $0.051 \pm 0.002$ & $1.09 \pm 0.06$ & 0.9998 & 0.44 & -0.002 & 0.15 \\
\hline & & burnt 4 & $1 \mathrm{yr}$ & $0.38 \pm 0.02$ & $0.078 \pm 0.006$ & $1.08 \pm 0.05$ & 0.9988 & -0.25 & 0.022 & -0.20 \\
\hline & & burnt 5 & $2 \mathrm{yr}$ & $3.59 \pm 0.10^{\mathrm{b}}$ & $0.019 \pm 0.001^{\mathrm{b}}$ & & $0.9976^{\mathrm{b}}$ & -1.76 & 0.002 & \\
\hline
\end{tabular}

${ }^{\mathrm{a}} \mathrm{C}_{t}=$ cumulative $\mathrm{C}$ released after time $t ; \mathrm{C}_{0}=$ labile $\mathrm{C}$ pool; $k=$ instantaneous mineralization rate of the labile $\mathrm{C}$ pool; $\mathrm{TC}=$ total $\mathrm{C} ; h=$ instantaneous mineralization rate of the recalcitrant $\mathrm{C}$ pool.

${ }^{\mathrm{b}}$ Values based on simple first order exponential equation $\mathrm{C}_{t}=\mathrm{C}_{0}\left(1-\mathrm{e}^{-k t}\right)$, because the asymptotic standard error based on double first order exponential equation surpassed $10 \%$ of the estimated values.

surface and killed by the fire, are very important for the recovery of soil organic matter.

Both soils showed an initial decrease in the $\mathrm{C} / \mathrm{N}$ ratio as a consequence of the fire (Tables 1 and 2; Fig. 2 ); this effect was observed in both layers, although it was more pronounced in the surface layer. $\mathrm{C} / \mathrm{N}$ ratios were already recovering during the first months after the wildfire, but they were always lower in the burnt soils than in the corresponding controls over the $2 \mathrm{yr}$, except for the burnt subsurface layer of soil $\mathrm{M}$, where $\mathrm{C} / \mathrm{N}$ ratios were higher than those of the control since $1 \mathrm{yr}$ after the fire, coinciding with the increase in the $\mathrm{C}$ concentration. The high values of the $\mathrm{C} / \mathrm{N}$ ratio in the subsurface layer of the burnt soil $\mathrm{M}$ suggest the incorporation of poorly humified organic matter into this layer and confirm the importance of the dead roots in the increase of $\mathrm{C}$ concentration after the fire.

\subsection{C mineralization activity}

In spite of their different altitudes and $\mathrm{C}$ concentrations, both unburnt soils $\mathrm{M}$ and $\mathrm{R}$ had similar $\mathrm{C}$ mineralization coefficients. The mean values of the $\mathrm{C}$ mineralization coefficient in the surface and the subsurface layers of these unburnt soils were, respectively,
2.76 and $1.98 \%$ of the total $\mathrm{C}$ in soil $\mathrm{M}$ and 3.16 and $2.22 \%$ of the total $\mathrm{C}$ in soil $\mathrm{R}$. These values indicate a low potential mineralization activity, as also reported by Carballas et al. (1979), Beloso et al. (1993) and Fernández et al. (1997) for undisturbed soils of the same zone.

Table 3 shows the cumulative amount of $\mathrm{C}$ mineralized and the $\mathrm{C}$ mineralization coefficient for the surface and the subsurface layers of the burnt $\mathrm{M}$ and $\mathrm{R}$ soils. The high $\mathrm{C}$ mineralization activity found in the fifth sampling of the burnt soil R (4.17 and $3.40 \%$ of the total $\mathrm{C}$ in the surface and the subsurface layers, respectively) coincided with the high values in the corresponding unburnt soil R (5.15 and 3.92\% of the total $\mathrm{C}$ in the surface and the subsurface layers, respectively); therefore, it must be mainly attributed to favourable climatic conditions, such as a high temperature and an adequate moisture content. The burning affected both activity indices. Immediately after the fire (soil $\mathrm{M}$ ) the $\mathrm{C}$ mineralization was decreased only in the surface layer (Fig. 3a). Afterwards, in the surface layers of both soils the $\mathrm{C}$ mineralization was also lower in the burnt area than in the unburnt area for almost the whole study period. In the subsurface layer 

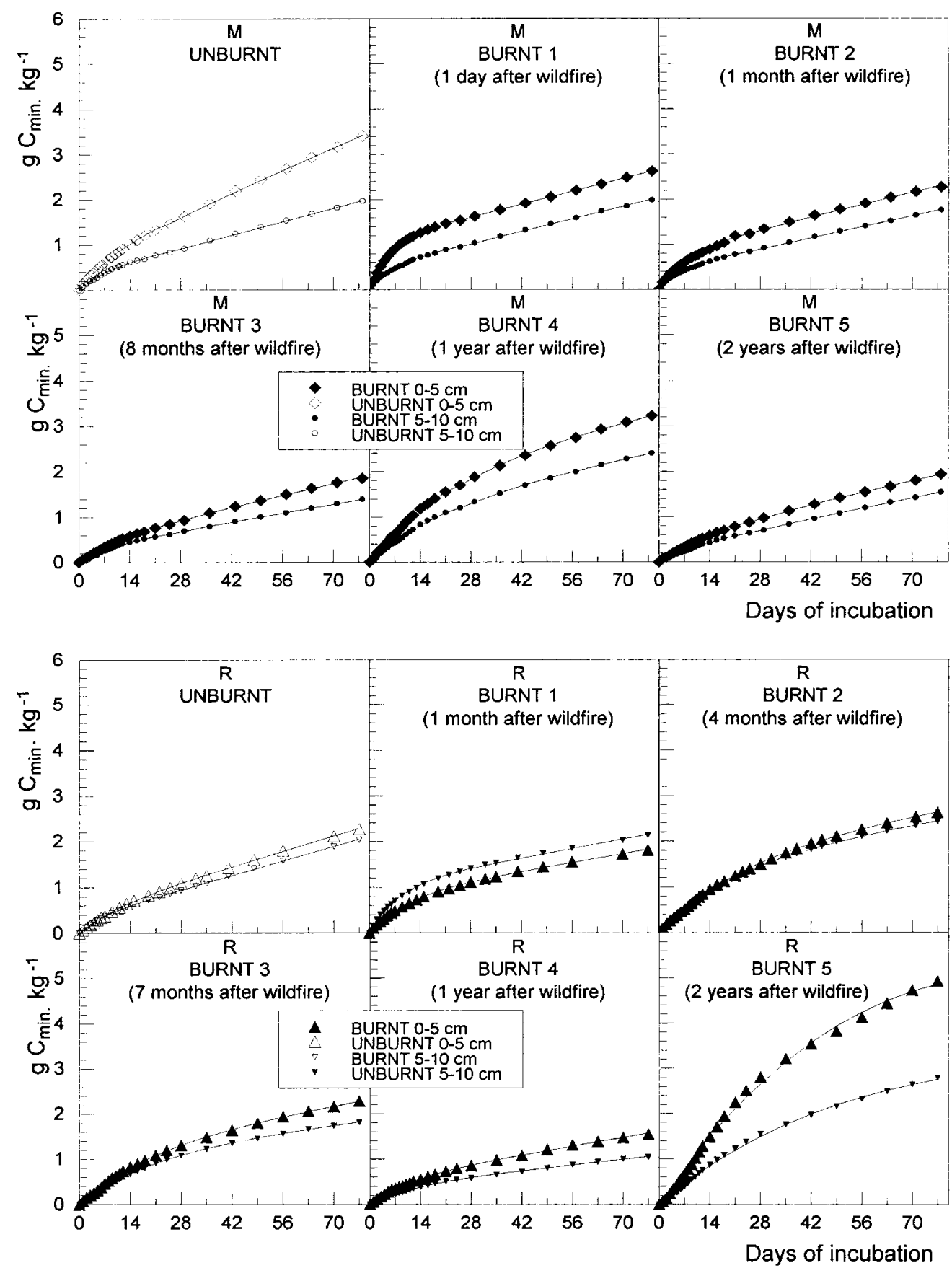

Fig. 4. Cumulative curves of the $\mathrm{C}$ mineralization during incubation of samples from the surface $(0-5 \mathrm{~cm})$ and the subsurface $(5-10 \mathrm{~cm})$ layers of the unburnt soils from the first sampling and of the burnt soils from the 5 samplings performed during $2 \mathrm{yr}$ after the wildfire. Lines correspond to the values predicted by the kinetic model and symbols correspond to the experimental values obtained during the incubation.

the $\mathrm{C}$ mineralization developed differently over time in the two soils. In soil $\mathrm{M}$ the $\mathrm{C}$ mineralization decreased in this layer during yr 1 after the fire and recovered 2 yr after the burning (Fig. 3a), whereas the $\mathrm{C}$ mineralization in soil $\mathrm{R}$ increased throughout the first months and presented values lower than those of the control since $1 \mathrm{yr}$ after the fire (Fig. 3c). This different behaviour was in agreement with the different input pat- terns of organic matter showed by both burnt soils, these inputs being earlier for soil $\mathrm{R}$ located at lower altitude and not affected by the winter freezing.

Despite the considerable increase observed immediately after burning, the $\mathrm{C}$ mineralization coefficient decreased abruptly 1 month after the fire in both layers of soil M (Fig. 3b). One month after the fire, the C mineralization coefficient in the surface layer of both 
soils was lower than that of the corresponding unburnt soil, this behaviour being maintained during the $2 \mathrm{yr}$ in soil $\mathrm{R}$, whereas in soil $\mathrm{M}$ the values were similar to those of the control from 8 months after the fire (Fig. $3 \mathrm{~b}$ and $\mathrm{d}$ ). In this layer, which was the most affected by the fire, when the initial increase in $\mathrm{C}$ mineralization coefficient disappeared, the organic matter became more resistant to biodegradation. A decrease in $\mathrm{C}$ mineralization coefficient $2 \mathrm{yr}$ after a wildfire was also found by Almendros et al. (1984) who attributed it to an increase in the humus stability, due to a relative decrease of the most easily biodegradable constituents. In the subsurface layers the $\mathrm{C}$ mineralization coefficients were maintained above those of the corresponding controls for several months in soil R (Fig. 3d) and throughout all the experiment in soil M (Fig. $3 \mathrm{~b}$ ). The burning also caused slightly higher values of the $\mathrm{C}$ mineralization coefficient in the subsurface layer than in the surface layer at the first samplings after the burning. The opposite was true for the unburnt soils, the values of the $\mathrm{C}$ mineralization coefficient for the subsurface layer of the control soils being always approximately $30 \%$ lower than those in the corresponding surface layers.

The two-way Anova applied separately to each sampling of both soils performed during the $2 \mathrm{yr}$ study, considering the five replicates of the $\mathrm{C}$ mineralization coefficient of each sample, indicated a significant interaction between both factors, fire and sampling depth, in all cases except for the fifth sampling of soil $\mathrm{R}$, carried out $2 \mathrm{yr}$ after the fire, where this interaction was not significant. This test also showed that the differences observed between the burnt and the corresponding unburnt samples were always statistically significant, except for the surface layer of soil $\mathrm{M}$ from 8 months after the fire and for both layers of soil R $2 \mathrm{yr}$ after the fire (Fig. 3b and d).

\subsection{C mineralization kinetics}

The cumulative values of $\mathrm{C}$ mineralization for soils $\mathrm{M}$ and $\mathrm{R}$ during incubation fitted the first-order equation of the simple exponential model and that of the double exponential model (Table 4; Fig. 4). In all cases the determination coefficients $\left(\mathrm{R}^{2}\right)$ were slightly higher for the double exponential model except for the fifth sampling of soil $\mathrm{R}$, the samples of which exhibited much higher mineralization activity. In this case the standard asymptotic error for the different parameters was very high and the mineralization kinetic fitted the simple exponential model better.

According to the kinetic parameters estimated for the double exponential model, the labile $\mathrm{C}$ pool $\left(\mathrm{C}_{0}\right)$ increased immediately after the fire (Table 4 , soil M 1d after the fire) and the increase was greater in the surface layer than in the subsurface layer (from 0.67 to
$1.06 \mathrm{~g} \mathrm{C}_{0} \mathrm{~kg}^{-1}$ soil and from 0.34 to $0.47 \mathrm{~g} \mathrm{C}_{0} \mathrm{~kg}^{-1}$ soil, respectively). The instantaneous mineralization rate of the labile fraction $(k)$, as well as that of the most recalcitrant pool of the organic matter $(h)$, also increased considerably in both layers immediately after the burning, this increase being higher in the surface layer for the former and higher in the subsurface layer for the latter. This agrees with the mineralization kinetics of both layers (Fig. 4: $\mathrm{M}$ burnt 1). The greater increase in the parameters $\mathrm{C}_{0}$ and $k$ for the surface layer $1 \mathrm{~d}$ after the fire resulted from the higher activity of this layer during the 2 first weeks of the incubation whereas the greater increase in the kinetic parameter $h$ for the subsurface layer resulted from the higher coefficient of mineralization for this layer at the last phase of the incubation, showing a total $\mathrm{C}$ mineralization higher than that of the surface layer (Table 3).

Although a general trend was observed in the $\mathrm{C}$ mineralization dynamics following the fire, it was not quite consistent for the two soils. In both layers of the burnt soil $\mathrm{M}$, the labile organic matter content decreased with time, reaching the lowest values 8 months after the fire, with $\mathrm{C}_{0}$ values lower than those of the corresponding unburnt soils; from here to the end of the experiment a tendency of recovery was observed for $\mathrm{C}_{0}$ (Table 4). The mineralization rate of the labile $\mathrm{C}(k)$, which had increased considerably immediately after the fire in soil $\mathrm{M}$, decreased throughout the first 12 months, exhibiting, 2 yr after the fire, values similar to those of the unburnt soils. The instantaneous mineralization rate of the resistant fraction $(h)$ was also modified by the fire, particularly in the subsurface layer where this parameter, which had increased strongly immediately after the fire, decreased during the first 8 months and was almost constant afterwards with values slightly higher than those of the unburnt soil.

Soil $\mathrm{R}$ exhibited increased $\mathrm{C}$ mineralization in both layers during the first stages of the incubation of samples collected 1 month after the fire, as shown by the high slopes of the cumulative curves for the burnt soil during the first 2 weeks of the incubation (Fig. 4: $\mathrm{R}$ burnt 1 ). This increase progressively disappeared, so that the slopes of the cumulative curves diminished and, after these first weeks of incubation, they became lower than those presented by the cumulative curves of the unburnt soil.

The high initial activity of the subsurface layer of soil $\mathrm{R}$, which was mainly observed in the first two samplings (1 month and 4 months) after the fire, coincided with the higher cumulative $\mathrm{C}$ mineralization and $\mathrm{C}$ mineralization coefficient exhibited by this layer at the end of the incubation, compared with both its control and the surface layer of the burnt soil itself (Table 3). High initial activity in the subsurface layer could be due to its enrichment with soluble com- 


\section{COMPONENT III}

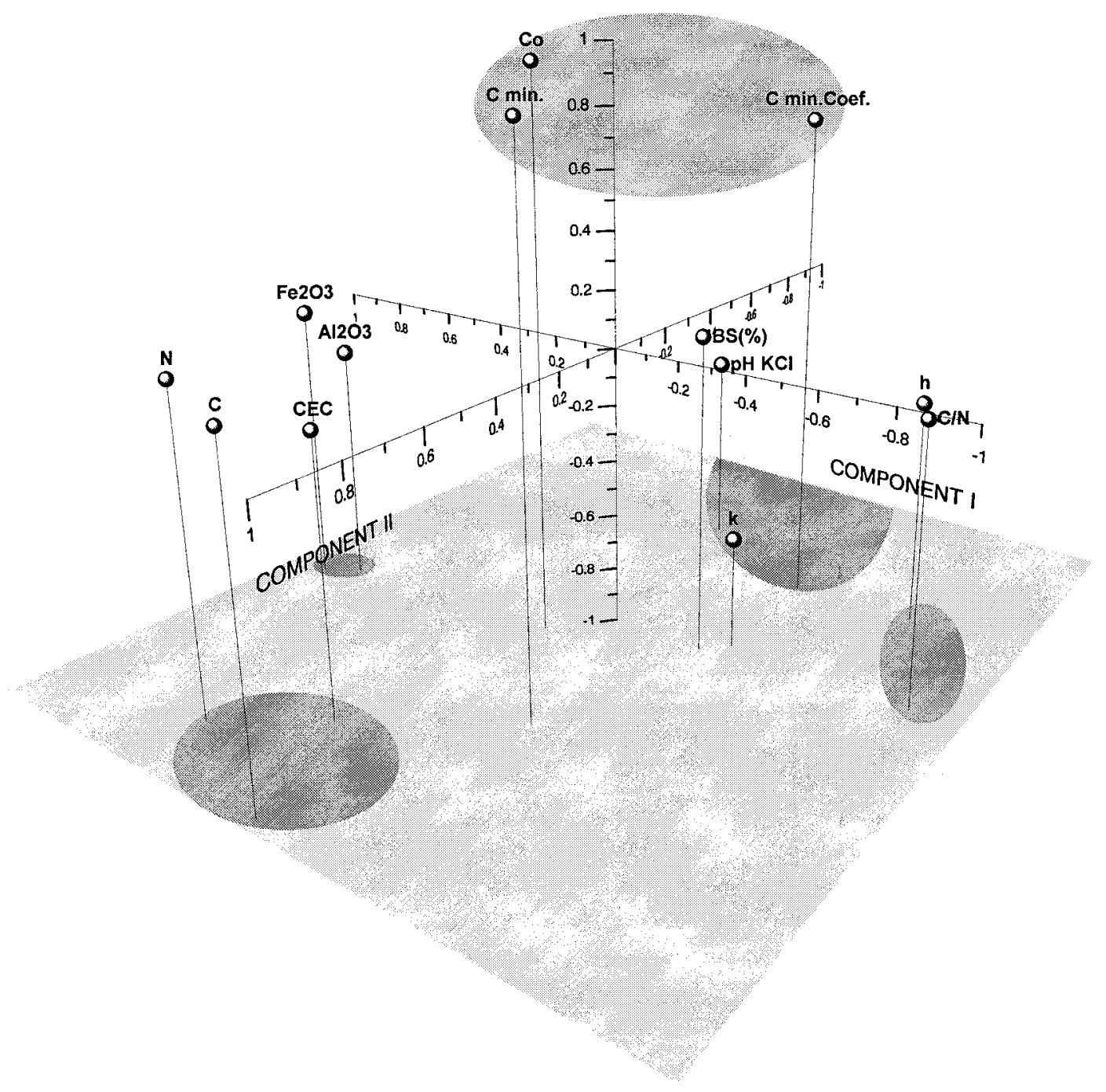

Fig. 5. Principal components analysis. Variable weightings in three principal components: $\mathrm{C}=$ carbon concentration; $\mathrm{N}=$ nitrogen concentration; $\mathrm{C} / \mathrm{N}=$ carbon/nitrogen ratio; $\mathrm{pH} \mathrm{KCl}=\mathrm{pH}$ in $\mathrm{KCl} ; \mathrm{Fe}_{2} \mathrm{O}_{3}=$ soluble $\mathrm{Fe}$ oxides; $\mathrm{Al}_{2} \mathrm{O}_{3}=$ soluble $\mathrm{Al}$ oxides; $\mathrm{CEC}=$ cation exchange capacity; $\mathrm{BS}(\%)=$ percentage of base saturation; $\mathrm{C}$ min. $=$ mineralized carbon $\mathrm{kg}^{-1}$ dry soil; $\mathrm{C}$ min. Coef. $=$ carbon mineralization coefficient; $\mathrm{C}_{0}=$ labile carbon; $\mathrm{k}=$ instantaneous mineralization rate for labile organic fractions; $\mathrm{h}=$ instantaneous mineralization rate for recalcitrant organic fractions.

pounds leached from the surface layer as a consequence of the heavy rain that took place between the fire and the first sampling. This is in agreement with the amount of water-soluble $\mathrm{C}$ compounds of the subsurface layer of the burnt soil $\mathrm{R}$ before incubation (0.64 $\mathrm{g} \mathrm{C} \mathrm{kg}^{-1}$ soil), which was twice that of the surface layer of the same soil $\left(0.33 \mathrm{~g} \mathrm{C} \mathrm{kg}^{-1}\right.$ soil $) 1$ month after the fire (I. Fernández, unpublished $\mathrm{PhD}$ thesis, University of Santiago de Compostela, 1997). In later samplings, when this enrichment disappeared, the $\mathrm{C}$ mineralization of the subsurface layer was lower than that of the surface layer and the $\mathrm{C}$ mineralization kinetics of both layers of the burnt soil were similar to those of the corresponding unburnt soil (Fig. 4).

In both layers of the burnt soil $\mathrm{R}$ the values of $\mathrm{C}_{0}$ for the first three samplings after the fire were higher than those exhibited by the corresponding samples of the unburnt soil (Table 4); however, this effect disappeared $1 \mathrm{yr}$ after the fire and $2 \mathrm{yr}$ after the burning the values of $\mathrm{C}_{0}$ were lower than those exhibited by the unburnt soil. During the whole period studied, the instantaneous mineralization rate of the labile pool $(k)$ was not consistently modified compared with that of the unburnt soil. The mineralization rate of the recalcitrant pool $(h)$, which had decreased 1 month after the fire in soil R, was generally lower than that in the unburnt soil during the study, this effect being greater in the surface layer.

The different behaviour of the $\mathrm{C}$ mineralization dynamics of both soils after burning was also shown 


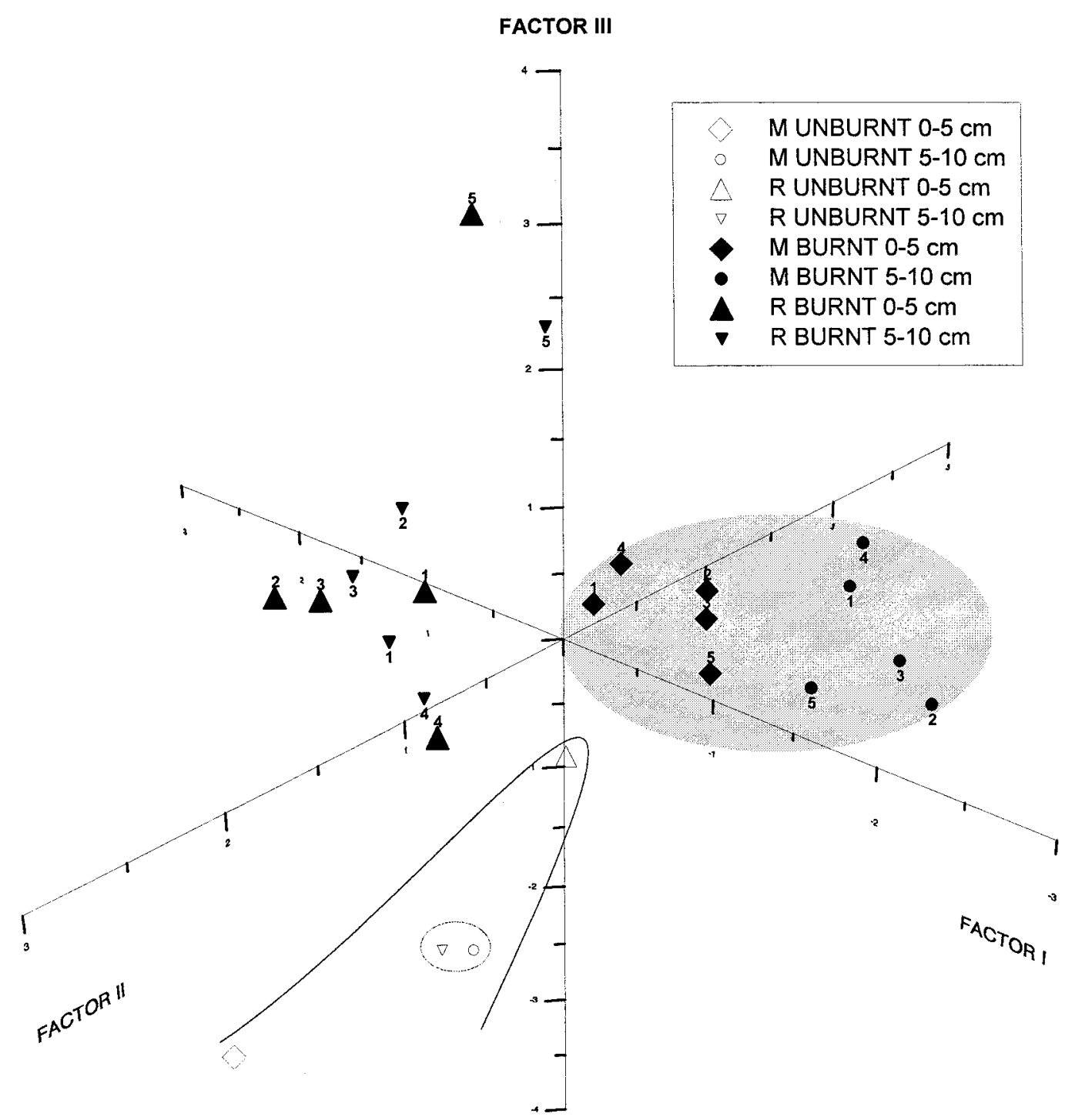

Fig. 6. Sample distribution based on PCA factor scores in the three-dimensional space defined by the three first components explaining $75.4 \%$ of the variance. The factor axes represent summaries of the variables on the component I, II and III axis, respectively and the sample distribution in this three-dimensional space shows sample grouping with respect to the variables in the PCA model (1, 2, 3, 4, 5: sampling number).

when the coefficients of correlation between the $\mathrm{C}$ mineralization at the end of the incubation and the kinetic parameter $\mathrm{C}_{0}$ for soils $\mathrm{M}$ and $\mathrm{R}$ were compared. In the burnt samples of soil $\mathrm{M}$, a significant positive correlation between these variables was observed $(r=0.965, P=0.000)$, whereas this was not true for the burnt samples of soil $\mathrm{R}$. The relative importance of the labile and resistant fractions on the total $\mathrm{C}$ mineralization differed for each soil; the total $\mathrm{C}$ mineralization of the burnt soil $\mathrm{M}$ was mainly determined by the mineralization of the labile fraction, whose instantaneous mineralization rate $(k)$ increased after the burning, whereas no fraction determines by itself the total $\mathrm{C}$ mineralization of the burnt soil $\mathrm{R}$.

The increased $\mathrm{C}$ mineralization coefficient after the fire (Fig. 3), could be attributed to the addition of labile organic substances to the burnt soil, in agreement with the predicted increase in $\mathrm{C}_{0}$ immediately after the fire. This labile organic matter, accessible to microorganisms and not easily renewed, is quickly metabolized and hence the increase in microbial activity disappears rapidly. The origin of the labile organic compounds could be the transformation of more recalcitrant ones. Almendros et al. (1988) found an increase in lipids of shorter chain $\left(<\mathrm{C}_{20}\right)$ after heating the soil at $210^{\circ} \mathrm{C}$. The increased $\mathrm{C}$ mineralization coefficient could be also related to the modification of the soil conditions that had favoured the microbiota development, such as an increase in soil $\mathrm{pH}$ after the fire or the addition of ashes to the soil which produces an 
ephemeral increase in nutrient availability (Marion et al., 1991; Prieto-Fernández et al., 1993; Fritze et al., 1994). In agreement with this, in both burnt soils studied $\mathrm{M}$ and $\mathrm{R}$ significant coefficients of correlation between the $\mathrm{pH}$ in $\mathrm{KCl}$ and the instantaneous mineralization rates of both labile and resistant fractions $(r=0.615, P=0.002$ for $k ; r=0.531, P=0.023$ for $h)$ and between the percentage of base saturation BS and the potentially mineralizable $\mathrm{C}$ in the labile pool $\mathrm{C}_{0}(r=0.724, P=0.000)$ were found. The increased mineralization coefficient after the fire was also in accordance with the microbial proliferation observed by Vázquez et al. (1993) for the same soils. Van Veen et al. (1989) found that microbial proliferation depends not only on the availability of the organic substrate but also on the amount of nutrients in the soil.

\subsection{Principal components analysis}

In order to obtain a more integrated understanding of the factors most directly related to the behaviour of the different samples studied, a principal components analysis (PCA) was used to examine the data.

Eigenvalues for the PCA, carried out with the five samplings of both burnt soils as well as the first sampling of the unburnt soils and 13 selected variables (pH KCl, C, N, C/N, CEC, BS, $\mathrm{Fe}_{2} \mathrm{O}_{3}, \mathrm{Al}_{2} \mathrm{O}_{3}, \mathrm{C}$ min., $\mathrm{C}$ min.Coef., $\mathrm{C}_{0}, k$ and $h$ ) indicated that the three first components accounted for $75 \%$ of total variance (Fig. 5). Component I, mainly related to the organic matter quality, explained more than $45 \%$ of the total variance. The most heavily weighted variables of this component were soluble $\mathrm{Fe}$ and $\mathrm{Al}$ oxides, at its positive extreme, and the $\mathrm{C} / \mathrm{N}$ ratio and the kinetic parameter $h$, at the negative extreme. This indicates that a high concentration of altered compounds is related to the more humified and more stabilized organic matter, showed by the lower $\mathrm{C} / \mathrm{N}$ ratio and the slower instantaneous mineralization rate of the recalcitrant fraction of the organic matter. The most heavily weighted variables of component II were those most related to the organic matter concentration, whereas practically only the variables related to the $\mathrm{C}$ mineralization activity were associated with component III. Therefore, this analysis shows that the main factor controlling the $\mathrm{C}$ mineralization of the burnt soils was the stability of the organic matter, due to high concentrations of $\mathrm{Al}$ oxides in these soils (Fernández et al., 1997).

Both unburnt soils are located in the same quadrant, quite close each other (Fig. 6), particularly the subsurface samples, since the surface samples are slightly separated due to their different total $\mathrm{C}$ concentration. The weighting of the variables separated the burnt and the unburnt samples as well as the burnt samples from soils $\mathrm{M}$ and $\mathrm{R}$. The burnt samples of soil $\mathrm{M}$ were placed in a well-defined zone of the three-dimensional space and their distribution along factor I separated the surface and the subsurface samples of this soil due to differences in their organic matter quality, whereas factor II clearly separated all the burnt samples from the unburnt soil due to the decrease in organic matter induced by the burning. Burnt samples of soil $\mathrm{R}$ were also clearly grouped, when excluding those from fifth sampling that were separated from the other samplings along factor III due to their high mineralization activity. In soil $\mathrm{R}$ the separation between the burnt and the unburnt samples was observed along factor I and there was no visible differentiation between the surface and the subsurface samples of the burnt soil. The main change due to the fire observed in soil $\mathrm{M}$ was a pronounced decrease in organic matter concentration, whereas the burning resulted in a stabilization of the organic matter and an increase in soluble $\mathrm{Fe}$ and $\mathrm{Al}$ oxides in soil $\mathrm{R}$. The greater separation observed between the burnt and the unburnt samples of soil $\mathrm{M}$ suggests that the effect of the fire was greater on soil $\mathrm{M}$ than on soil $\mathrm{R}$, which would indicate a greater intensity wildfire. The close location of the burnt samples from each soil suggests the persistence of the burning effects during the $2 \mathrm{yr}$ study.

\section{Conclusions}

Besides the initial effect of fire, a decrease of the C mineralization and an increase of the $\mathrm{C}$ mineralization coefficient, the mineralization activity indices were altered for at least $2 \mathrm{yr}$ after the fire in both soil layers studied. The total $\mathrm{C}$ mineralization of the burnt soil $\mathrm{M}$ was mainly determined by the mineralization of the labile fraction of its organic matter, whereas no fraction determines by itself the total $\mathrm{C}$ mineralization of the burnt soil R. Although the evolution of the $\mathrm{C}$ mineralization differed in soils $\mathrm{M}$ and $\mathrm{R}$, two important effects were observed: an initial increase of the organic matter lability (increases of $\mathrm{C}_{0}$ and $k$ ), which was ephemeral, and a subsequent and more persistent increase of the organic matter stabilization. The instantaneous mineralization rate of the more recalcitrant organic matter $(h)$ showed that the surface layer of the burnt soils was not still recovered $2 \mathrm{yr}$ after the fire, when the revegetation had already started and the $\mathrm{C}$ concentration was almost recovered, suggesting the presence of soil organic matter of different quality. In the subsurface layer neither the $\mathrm{C}$ concentration nor the kinetic parameter $h$ had totally recovered $2 \mathrm{yr}$ after the fire.

\section{Acknowledgements}

The authors thank Mr J. Salmonte and Ms B. 
Arnáiz for technical assistance. This research was supported by the Consellería de Educación y Ordenación Universitaria de la Xunta de Galicia and by the Comisión Interministerial de Ciencia y Tecnología (CICYT), Spain.

\section{References}

Almendros, G., Polo, A., Ibáñez, J.J., Lobo, M.C., 1984. Contribución al estudio de la influencia de los incendios forestales en las características de la materia orgánica del suelo. Revue d'Ecologie et Biologie du Sol 21, 7-20.

Almendros, G., Martin, F., González-Vila, F.J., 1988. Effects of fire on humic and lipid fractions in a dystric xerochrept in Spain. Geoderma 42, 115-127.

Andrén, O., Paustian, K., 1987. Barley straw decomposition in the field: a comparison of models. Ecology 68, 1190-1200.

Bauhus, J., Khanna, P.K., Raison, J., 1993. The effect of fire on carbon and nitrogen mineralization and nitrification in an australian forest soil. Australian Journal of Soil Research 31, 621-639.

Bekku, Y., Koizumi, H., Oikawa, T., Iwaki, H., 1996. Examination of four methods for measuring soil respiration. Applied Soil Ecology 5, 247-254.

Beloso, M.C., Villar, M.C., Cabaneiro, A., Carballas, M., GonzálezPrieto, S.J., Carballas, T., 1993. Carbon and nitrogen mineralization in an acid soil fertilized with composted urban refuses. Bioresource Technology 45, 123-129.

Berg, B., Tamm, C.O., 1991. Decomposition and nutrient dynamics of litter in long-term optimum nutrition experiments. I. Organic matter decomposition in Picea abies needle litter. Scandinavian Journal of Forest Research 10, 108-109.

Bremner, J.M., 1965. Nitrogen availability indexes. In: Black, C.A., Evans, D.D., White, J.L., Ensminger, L.E., Clark, F.E. (Eds.), Methods of Soil Analysis. Part 2. Chemical and Microbiological Properties. American Society of Agronomy, Madison, pp. 13241345.

Carballas, M., Carballas, T., Jacquin, F., 1979. Biodegradation and humification of organic matter in humiferous atlantic soils. Anales de Edafología y Agrobiologia 38, 1699-1717.

Casal, M., 1985. Cambios en la vegetación de matorral tras el incendio en Galicia. In: ICONA (Ed.), Estudios sobre prevención y efectos ecológicos de los incendios forestales. Servicio de Publicaciones Agrarias, Ministerio de Agricultura, Pesca y Alimentación, Madrid, pp. 93-101.

Chandler, C., Cheney, P., Thomas, P., Trabaud, L., Williams, D., 1983. Fire in Forestry. Vol. I. Forest Fire Behavior and Effects. John Wiley, New York.

Choné, T., Jacquin, F., Yagui, M., 1974. Emploi de ${ }^{14} \mathrm{C}$ et ${ }^{45} \mathrm{Ca}$ comme éléments traceur de l'humification. Bulletin de l'Ecole Nationale Superieure d'Agronomie et des Industries Alimentaires de Nancy 15, 69-85.

Díaz-Fierros, F., Gil-Sotres, F., Cabaneiro, A., Carballas, T., Leirós, M.C., Villar, M.C., 1982. Efectos erosivos de los incendios forestales en suelos de Galicia. Anales de Edafología y Agrobiología 41, 627-639.

Fernández, I., Cabaneiro, A., Carballas, T., 1997. Organic matter changes immediately after a wildfire in an atlantic forest soil and comparison with laboratory soil heating. Soil Biology \& Biochemistry 29, 1-11.

Franzluebbers, A.J., Arshad, M.A., 1997. Particulate organic carbon content and potential mineralization as affected by tillage and texture. Soil Science Society of America Journal 61, 1382-1386.

Fritze, H., Smolander, A., Levula, T., Kitunen, V., Mälkönen, E., 1994. Wood-ash fertilization and fire treatments in a Scots pine forest stand: effects on the organic layer, microbial biomass and microbial activity. Biology and Fertility of Soils 17, 57-63.

González-Prieto, S.J., Carballas, M., Carballas, T., 1991. Mineralization of a nitrogen-bearing organic substrate model ${ }^{14} \mathrm{C}$, ${ }^{15} \mathrm{~N}$-glycine in two acid soils. Soil Biology \& Biochemistry 23, 5363.

Guckert, A., Roger, P., Jacquin, F., 1968. Contribution à l'utilisation de techniques radioisotopiques pour l'étude de la matière organique du sol. Bulletin de l'Ecole Nationale Superieure d'Agronomie et des Industries Alimentaires de Nancy 10, 69-100.

Guitián Ojea, F., Carballas, T., 1976. Técnicas de Análisis de Suelos. Pico Sacro, Santiago de Compostela.

Guitián Ojea, F., Carballas, T., 1982. Suelos Naturales de la Provincia de Orense. CSIC, Madrid.

Guitián Ojea, F., Muñoz, M., Carballas, T., 1986. Suelos naturales de la provincia de Pontevedra. In: Misión Biológica de Galicia (Ed.), Estudio Agrobiológico de la Provincia de Pontevedra. CSIC, Pontevedra, pp. 89-171.

Marion, G.M., Moreno, J.M., Oechel, W.C., 1991. Fire severity, ash deposition and clipping effects on soil nutrients in chaparral. Soil Science Society of America Journal 55, 235-240.

Merilä, P., Ohtonen, R., 1997. Soil microbial activity in the coastal Norway spruce (Pinea abies (L.) Karst.) forests of the Gulf of Bothnia in relation to humus-layer quality, moisture and soil types. Biology and Fertility of Soils 25, 361-365.

Pastor, J., Post, W.M., 1986. Influence of climate, soil moisture and succession on forest carbon and nitrogen cycles. Biogeochemistry 2, 3-27.

Pomazkina, L.V., Lubnina, E.V., Zorina, S.Y., Kotova, L.G., 1996. Dynamics of $\mathrm{CO}_{2}$ evolution in grey forest soil of the Baikal forest-steppe. Biology and Fertility of Soils 23, 327-331.

Prieto-Fernández, A., Villar, M.C., Carballas, M., Carballas, T., 1993. Short-term effects of a wildfire on the nitrogen status and its mineralization kinetics in an atlantic forest soil. Soil Biology \& Biochemistry 25, 1657-1664.

Rovira, R., Vallejo, V.R., 1997. Organic carbon and nitrogen mineralization under mediterranean climatic conditions: the effects of incubation depth. Soil Biology \& Biochemistry 29, 1509-1520.

Sampson, R.N., 1995. Designing forestry projects for climate action plan implementation. Interciencia 20, 373.

Sanroque, P., Rubio, J.L., Mansanet, J., 1985. Efectos de los incendios forestales en las propiedades del suelo, en la composición florística y en la erosión hídrica de zonas forestales de Valencia (España). Revue d'Ecologie et de Biologie du Sol 22, 131-147.

Stanford, G., Smith, S.J., 1972. Nitrogen mineralization potentials of soils. Soil Science Society of America Proceedings 36, 465-472.

Trabaud, L., 1983. The effect of different fire regimes on soil nutrient levels in Quercus coccifera garrigue. In: Kruger, F.J., Mitchell, D.T., Jarvis, J.U.M. (Eds.), Mediterranea-type Ecosystems. The Role of Nutrients. Springer-Verlag, Berlin, pp. 233-243.

Tukey, S.W., 1953. The Problem of Multiple Comparisons. Princeton University Press, Princeton.

Updegraff, K., Pastor, J., Bridgham, S.D., Johnston, A., 1995. Environmental and substrate controls over carbon and nitrogen mineralization in northern wetlands. Ecological Applications 5, 151-163.

Van Veen, J.A., Merckx, R., Van de Geijn, S.C., 1989. Plant- and soil related controls of the flow of carbon from roots through the soil microbial biomass. Plant and Soil 115, 179-188.

Vázquez, F.J., Acea, M.J., Carballas, T., 1993. Soil microbial populations after wildfire. FEMS Microbiology Ecology 13, 93-104.

Wardle, D.A., 1992. A comparative assessment of factors which influence microbial biomass carbon and nitrogen levels in soil. Biological Reviews of the Cambridge Philosophical Society 67, 321-358.

Wen, G., Voroney, R.P., Winter, J.P., Bates, T.E., 1997. Effects of 
irradiation on sludge organic carbon and nitrogen mineralization. Soil Biology \& Biochemistry 29, 1363-1370.

Wildung, R.E., Garland, T.R., Buschborn, R.L., 1975. The interdependent effects of soil temperature and water content on soil res- piration rate and plant root decomposition in arid grassland soils. Soil Biology \& Biochemistry 7, 373-378.

Winjum, J.K., Schroeder, P.E., 1997. Forest plantations in the world: Their extend, ecological attributes and carbon storage. Agricultural and Forest Meteorology 84, 153-167. 